\title{
Who Cares About Local Candidates? Finding Voters That Use Candidate Localness As A Cue For Their Vote Choices*
}

\author{
Sofia Collignon-Delmar ${ }^{\dagger 1}$ and Javier Sajuria ${ }^{\ddagger 2}$ \\ ${ }^{1}$ Department of Politics and International Relations, Royal Holloway University of London, UK \\ ${ }^{2}$ School of Politics and International Relations, Queen Mary, University of London, UK
}

January 23, 2018

\begin{abstract}
The literature on candidate selection has found that voters favour local candidates, as they are thought to be more apt to represent their constituents. An important caveat is that it requires for a voter to have knowledge of the candidates' characteristics, and to value localism. Previous research concentrates on candidate characteristics, leaving unanswered the question of who considers localism to be important when making their vote choices. This research fills the gap by showing that not all voters care in the same degree and magnitude about localism. We test this argument analysing data from the British Election Survey 2015 using multilevel models. Results show that voters who feel stronger about their distinctive regional identities care significantly more about localism. Additionally, this effect is different when the party system includes a party that explicitly channels these feelings, suggesting that the advantage of local candidates is dependent on the context of party competition.
\end{abstract}

Keywords: Multilevel models, candidate competence, voting behaviour, descriptive representation

*We are grateful to Jon Mellon and Ruth Dassonneville for their feedback on previous versions of this paper. Authors are in alphabetic order. Both contributed in equal degree to the article. This is a draft version. 2,680 words

${ }^{\dagger}$ E-mail: sofia.collignon@rhul.ac.uk

†E-mail: j.sajuria@qmul.ac.uk; Corresponding author 


\section{Introduction}

Candidate attributes are a salient concern in every election; they reflect directly on the level of descriptive representation of particular groups. Furthermore, descriptive representation matters because it improves the relationship between voters and representatives (Phillips, 1995). In recent years, concerns about representation have gone beyond gender and ethnicity (Reynolds, 2005) to include the study of local representation (Childs and Cowley, 2011). The predominant theory is that local representatives are better equipped to represent the interests of the constituency because they are more knowledgeable about local needs (Tavits, 2010; Shugart et al., 2005). In particular, political science has examined the effect of localness on electoral success and how this effect varies as a function of district magnitude (Shugart et al., 2005), following the principle that being perceived as local candidate is an advantage and a meaningful signal for voters (Jankowski, 2016). This is because local candidates will be able to break party discipline as they rely less in their party for future career and because local ties can help make the elected official accountable to the constituency (Tavits, 2010; Campbell and Cowley, 2014). Other important empirical work on localness has focused on the traits of local candidates that matter to voters (Arzheimer and Evans, 2012; Campbell and Cowley, 2014; Glasgow and Alvarez, 2000) and in disentangling the effect of localness to "friends and neighbour effects" that are endogenous to canvasing activities, which explains why candidates' success vary systematically as a function of their residence (Górecki and Marsh, 2012; Arzheimer and Evans, 2012).

Results generally point to a positive relationship between localness and electoral success, suggesting that local candidates have an advantage over non-local candidates (Campbell and Cowley, 2014; Arzheimer and Evans, 2012; Jankowski, 2016; Rüdig et al., 2016). However, it seems to be a tenuous relationship among partisans, who. in their majority, support their party regardless of the quality of the local candidate (Roy and Alcantara, 2015; Blais and 
Daoust, 2017), suggesting that some individuals care more than others about localness (Blais et al., 2003; Blais and Daoust, 2017). However, research on which voters care about localness and use it as a cue to vote is still scarce.

Until recently, the salience of localness in voter's choice has received limited attention in the literature (Blais et al., 2003; Marsh, 2007; Górecki and Marsh, 2012). Blais and Daoust (2017) show that one in 10 Canadian voters like a local candidate from another party and in two out of five of these cases the preference for a local candidate trumped party preferences. It has been found that in general, personal activity is less important than party activity at the local level in Australia (McAllister, 2015), while in Canada 5\% of the electorate favour the local candidate, especially among rural and highly sophisticated voters (Blais et al., 2003), and in Ireland around 40\% of voters are candidate-centred (Marsh, 2007). Roy and Alcantara (2015) show evidence that support the existence of candidate effects but that the magnitude of this effect varies among voters. Their research suggests that voters that pay more attention to campaigns are more likely to support a strong local candidate and this effect is larger among party supporters. While their findings deepen our understanding of preferences for strong local candidates by expanding focus on partisanship, it is difficult to attribute these effects to the salience of descriptive representation because they rely on an experiment that only contrasts a strong local candidate versus two weaker candidates. Moreover, the restricted variation in the demographic composition of participants (all of them are Canadian University students), leaves the door open to explore this issue further. Thus, despite of important advances made by the literature in showing the advantage of local candidates, it is still pending to understand the reasons that voters have to support them. We still cannot discern for example, whether the presence of a local candidate can override tactical voting, or whether local voters that feel more strongly their local identity are more likely to vote for the local candidate than voters with more global or wider identities.

Contributing to our understanding of the advantages of local candidates, demographic 
representation and voting behaviour, we build on this previous work by identifying the characteristics of voters that are more likely to consider localness as an important cue to vote, an issue of high relevance previously identified by Childs and Cowley (2011).In this article we focus on the role of identities, specifically in regional identities ${ }^{1}$, in shaping preferences for the local candidate. We argue here that preferences for the local candidate depend on how strongly voters feel their distinctive regional identity.

Territorial identities are shaped during early socialisation and are constructed of shared experiences, culture, language and a particular sense of belonging while emphasising ingroup similarities and out-group-differences (Dovi, 2002; Bamberg et al., 2011; Schnaudt et al., 2016). Territorial identities have been traditionally used to explain attitudes towards the European Union (Hooghe and Marks, 2005, 2004; Carey, 2002) and recently, the Brexit referendum in the UK (Hobolt, 2016), for example. Their effect on vote choice is manifested in the distinctive voting patterns and party systems present in different regions of the UK, Belgium and Spain (Bassi et al., 2011; Chernyha and Burg, 2012; Dandoy and Schakel, 2013). We build on these studies to argue that territorial identities can shape preferences for local candidates and explain why some voters care more than others about their candidates being local.

Nation-states are not the only territorial units that citizen's may identify with. They can also identify with their regions, locality and community (Westle, 2011; Schnaudt et al., 2016). Recent research suggest that territorial identities are not always exclusive as voters can identify with multiple locations. However, in countries with strong regional cleavages or where regional politics have traditionally been confrontational, voters do feel their regional identities stronger than nation-state identities (Schnaudt et al., 2016). By appealing to voter's sense of belonging and their tendency towards homophilia (Bishop, 2008) is that

\footnotetext{
${ }^{1}$ We use the term regional identity for clarity purposes to be able to differentiate sub-national and national identities. However, in the UK context, Scottish, English, Welsh and Northern Ireland identities are referred to as national identities as they correspond to the four nations that form the United Kingdom.
} 
regional identities can shape preferences for local candidates (Childs and Cowley, 2011; Dovi, 2002).

We focus on regional identities over local identities as the former are not necessarily constituency bounded. Constituency boundaries are re-shaped continuously (in the particular case of the UK 2015 General Election, the constituency boundaries where in place since one election before) but regional boundaries are stable. This stability in boundaries facilitate the developing of a distinctive culture and shared experiences that are the basis for a a sense of belonging (Schnaudt et al., 2016). The literature (Kumar, 2003; Tilley et al., 2004; Schnaudt et al., 2016) also shows that, in the UK, there is a clear empirical and conceptual difference between English, Scottish, Welsh, and Irish identities (Hobolt, 2016; McCrone and Bechhofer, 2015), which give place for feelings that emphasise the in-group similarities and out-group differences in greater degree than constituency boundaries can do. Both elements, the identities differentiation together with more stability in their boundaries, allow individuals to develop stronger identities attached to their region that can be expressed as preferences for a local candidate. Thus, if the mechanism we are proposing holds, we can expect that voters that feel stronger their regional identity will care more about candidates being perceived as local.

To determine whether a candidate is local or not, previous empirical studies have mainly used information of candidate's place of residence, the geographical distance between the place of birth and the constituency where the candidate is standing or information about experience working as local council member or local assembly (see for example, Górecki and Marsh (2012); Arzheimer and Evans (2012); Tavits (2010). However, the personal characteristics of a candidate matter only when voters use those cues to vote (Shugart et al., 2005; Rüdig et al., 2016) and voters are likely to use additional information to evaluate localness of a candidate. To account for this we use, instead, information of voters own views of the importance of localness. Additionally, other researchers have mentioned that the effect of 
localness in voting behaviour is endogenous to to canvasing activities (Górecki and Marsh, 2012; Arzheimer and Evans, 2012). We instead, take advantage of the particularities of the BES 2015 survey design to circumvent this issue. In particular, the fact that the survey took place before the General Election 2015 campaign started, allowing us to isolate the importance of localness from canvasing activities. This permit us to offer a parsimonious model to identify voters who care about localness.

Results confirm previous research that suggested that not all voters care in the same degree and magnitude about candidate localness. They suggest that voters who feel strongly their regional identity care significantly more about this than voters who feel weakly about it, Additionally, we found that electoral choice is affected by the structure of the party system and that the presence of a nationalistic party, such as the Scottish National Party, can outweigh these feelings, probably because it channels regional identities and nationalistic feelings trough a different route. The conclusions support arguments advocated by Mann and Fenton (2017), that a certain "resentful nationalism" was growing in strength in England, but not in Scotland and Wales, which is currently playing a new part in English and British politics. Results also confirm the advantage of the local candidate and add a new layer to be considered to achieve better descriptive representation.

\section{Empirical Strategy and Data}

We used data from three main sources: the 4th wave of the British Election Study (BES) (Fieldhouse and Prosser, 2016), the Statements of Persons Nominated (SOPNs) that contain the candidates addresses ${ }^{2}$, the Office for National Statistics (ONS) Postcode dataset, and the BES 2015 Results Dataset (Fieldhouse and Prosser, 2015). The BES wave used for

\footnotetext{
${ }^{2}$ SOPNs are the official declarations issued by the local authorities in which they publish the candidates information. Candidates are asked to disclose their home addresses so they can be published in the SOPNs. If they refuse, the SOPNs will mention their constituency of residence.
} 
this paper was conducted during March 2015, and contains specific questions regarding the preference for local MPs and candidates. In particular, as our response variable we use a question asking respondents to rank from 0 to 10 the importance they assign to having a MP that is local. The mean score is relatively high, 7.8, with a standard deviation of 2.2.

The strength of regional identification is measured through 1-7 scales. The BES asks respondents in England, Scotland and Wales about how much English, Scottish, or Welsh they feel. The scale goes from 1 for "Not at all [English, Scottish, Welsh]", to 7 for "Very Strongly [English, Scottish, Welsh]". Party identification has been signalled as an important element of the preferences for local candidates (Roy and Alcantara, 2015), and is measured through a question in which respondents are asked to identify themselves as supporters of some of the main UK parties. We use their first responses, and for those respondents who do not provide a party the first time they are asked, we use the "squeezed" response (i.e. the response they give when asked "Do you generally think of yourself as a little closer to one of the parties than the others? If yes, which party?").

We also created a variable that measures whether the candidate who belongs to the respondents' preferred parties where local. This variable was constructed using the information from the SOPNs. For those candidates that provided their address, we matched their postcodes to the ONS postcodes dataset to determine whether the candidate lived in the constituency they were competing. With that information, we used the BES respondents declared vote preferences (variable generalElection Vote) to match if their preferred candidate was local or not.

Finally, we included some traditional controls, such as the age of the respondents, their levels of education (measured as their age when they finished their final degree), their selfdeclared sex (as a binary option), their ethnicity (as a binary variable), their interest in the upcoming election, and their self-declared position in a left to right scale. In general, we aimed to create parsimonious models to account for the relevance of localism. 
We employ multilevel hierarchical models to explore what characteristics of voters make them more likely to favour local candidates. Multilevel models are suitable to analyse the data at hand as they allow us to obtain average effects for individual characteristics and to use varying slopes to see how these effects vary in the different countries of the UK (excluding Northern Ireland), as opposed as assuming that all voters care in the same magnitude and intensity about localism. Additionally, this strategy allow us tap into the regional identities that form the UK. We use both varying intercepts and slopes by country. The varying slopes are used to analyse whether the association between caring for local MPs and the strength of regional identity holds across different countries in the UK. The use of a small number of units at the upper-level is a contested issue in the literature of hierarchical models. Stegmueller (Stegmueller, 2013) argues that frequentist approaches using maximum likelihood can produce biased estimates when the number of groups is low. He argues for the use of Bayesian methods to avoid these problems. Notwithstanding, recent research (Elff et al., 2016) refutes that claim and recommends the use of restricted maximum likelihood techniques, which is the approach we follow here.

The purpose of our empirical strategy is twofold. On the one hand, to test the different propositions about what drives the preference for local MPs. On the other hand, we are interested in observing the differences across the countries within the UK. This is particularly relevant as the difference in political preferences, particularly between Scotland and England, have been recently exposed in a sharp manner during the Brexit referendum. While England showed a majority vote for the Conservative party in 2015, and in favour of leaving the EU in 2016, Scotland elected 56 MPs from the Scottish National Party out of the 59 seats available and showed strong support for remaining in the EU $(62 \%)$ 


\section{Discussion of Results}

Table 1 shows the results form the multilevel models. As shown in Model 1, the relationship between regional identification and the preference for local MPs is positive and significant, which is consistent with our expectations. This effect holds all the way until Model 3, when we add all the different controls. In general, we show that there is an average effect across the whole of the UK, even when we control for the between-country variation through the use of varying intercepts. However, Model 4 shows a different picture. The average effect becomes non-significant after we allow the relationship to vary in each different country.

We explore this result in more detail in Figures 1 and 2. Figure 1 shows that the coefficients for the varying intercepts are not significantly different the average effect from Model 4. However, there is an important difference between the average effect and the incountry effect of regional identity. The coefficient shows a significant variation of 0.05 form the average effect, which is translated in a change in the slope, as it can be observed in Figure 2. The dotted lines represent Scotland and Wales, that show a much flatter slope than England. In particular, an increase in English regional identity from 1 to 7 leads to an increase in 1.6 points in the dependent variable at the individual level.

Party identification is also a relevant predictor, but in a very constrained case. As we can observe form Model 4 in Table 1, supporters of the Scottish National Party (SNP) are the only ones that show a significant preference for local MPs. This result reinforces the notion of regional differences in the dependent variable. However, unlike voters in England, where the preference seems to be driven by regional identification, the regional difference is here expressed as a preference for the nationalist party.

Unsurprisingly, if the preferred candidate is local, voters are more likely to prefer local MPs. The direction of this relationship is not necessarily clear, as the opposite can also be true: if voters prefer local MPs, they might choose local candidates. We believe that 


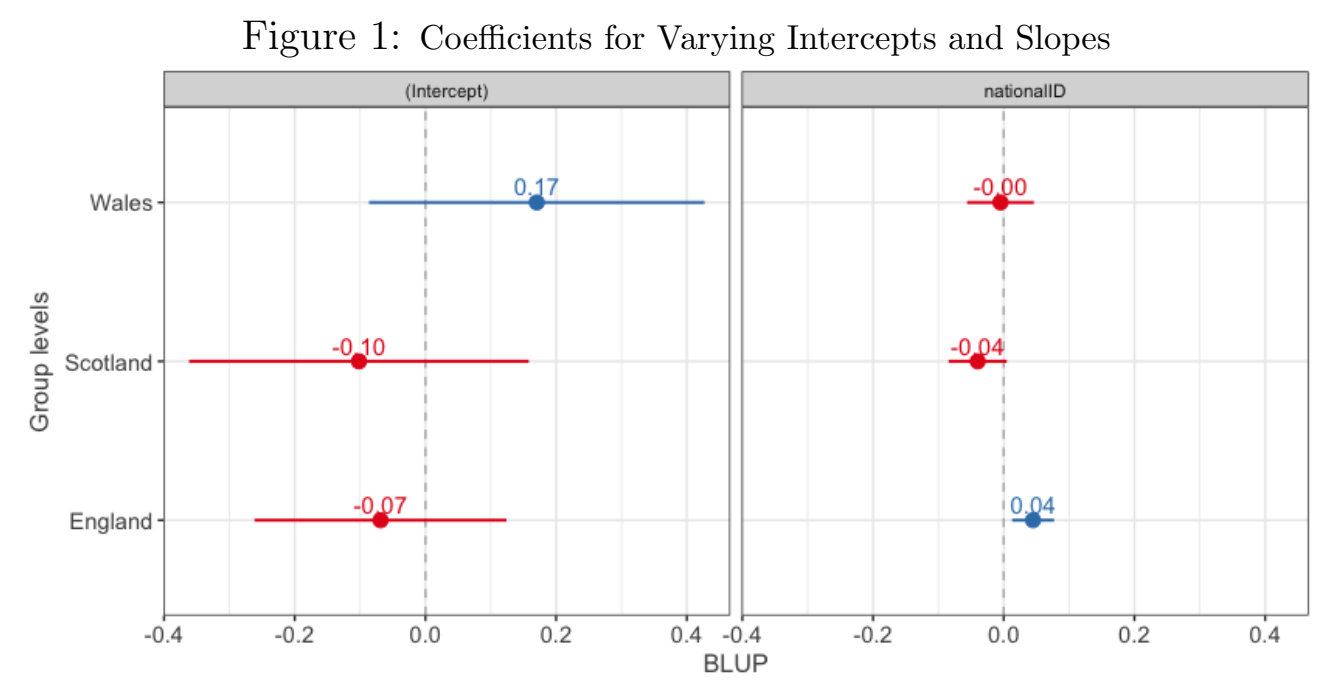

Figure 2: Varying Intercepts and Slopes for strength of Regional Identification by Country

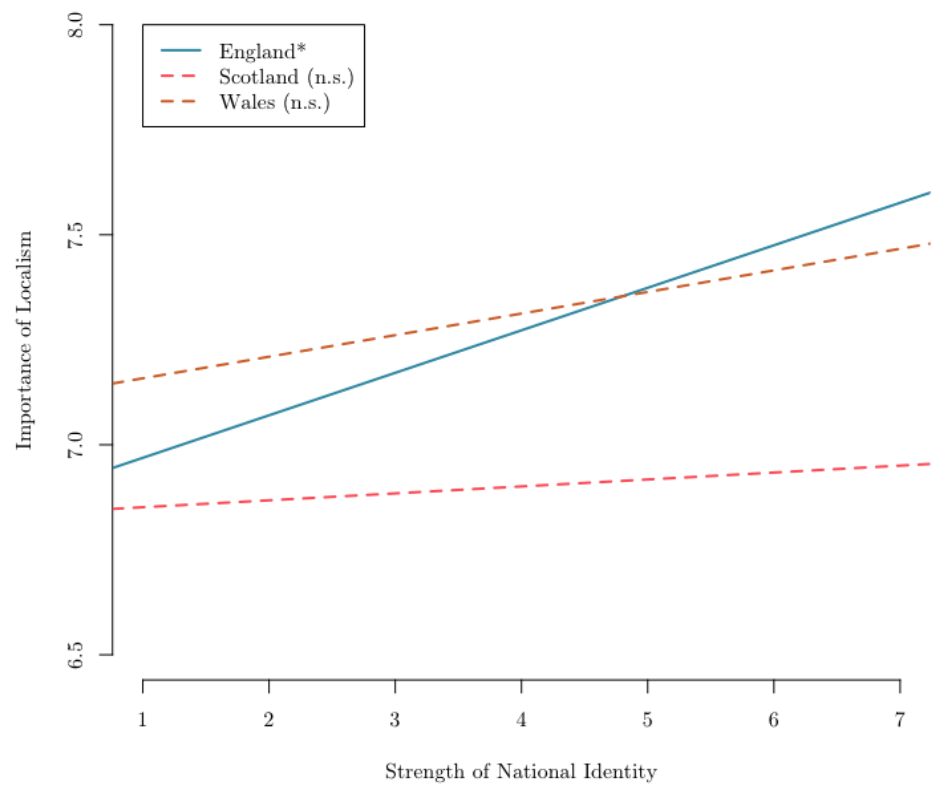


this results are slightly more in favour of the second interpretation. The fourth wave of the BES was conducted before the campaign period, where most candidates were still unknown for most of the voters. Their voting preferences were asked in terms of their preferred political parties, without mentioning individual candidates or their characteristics. Thus, we should expect that if they are consistent with their attitudes, they would later choose local candidates over those who are not, but this idea remains untested here.

Finally, more educated respondents are less focused on the local character of their MPs, while women are more likely to prefer local MPs than men. These effects hold across the ideological spectrum: Left-right position of voters and their ethnicity do not make any difference to the result, while interest in the election is positively related to preference for local MPs. 


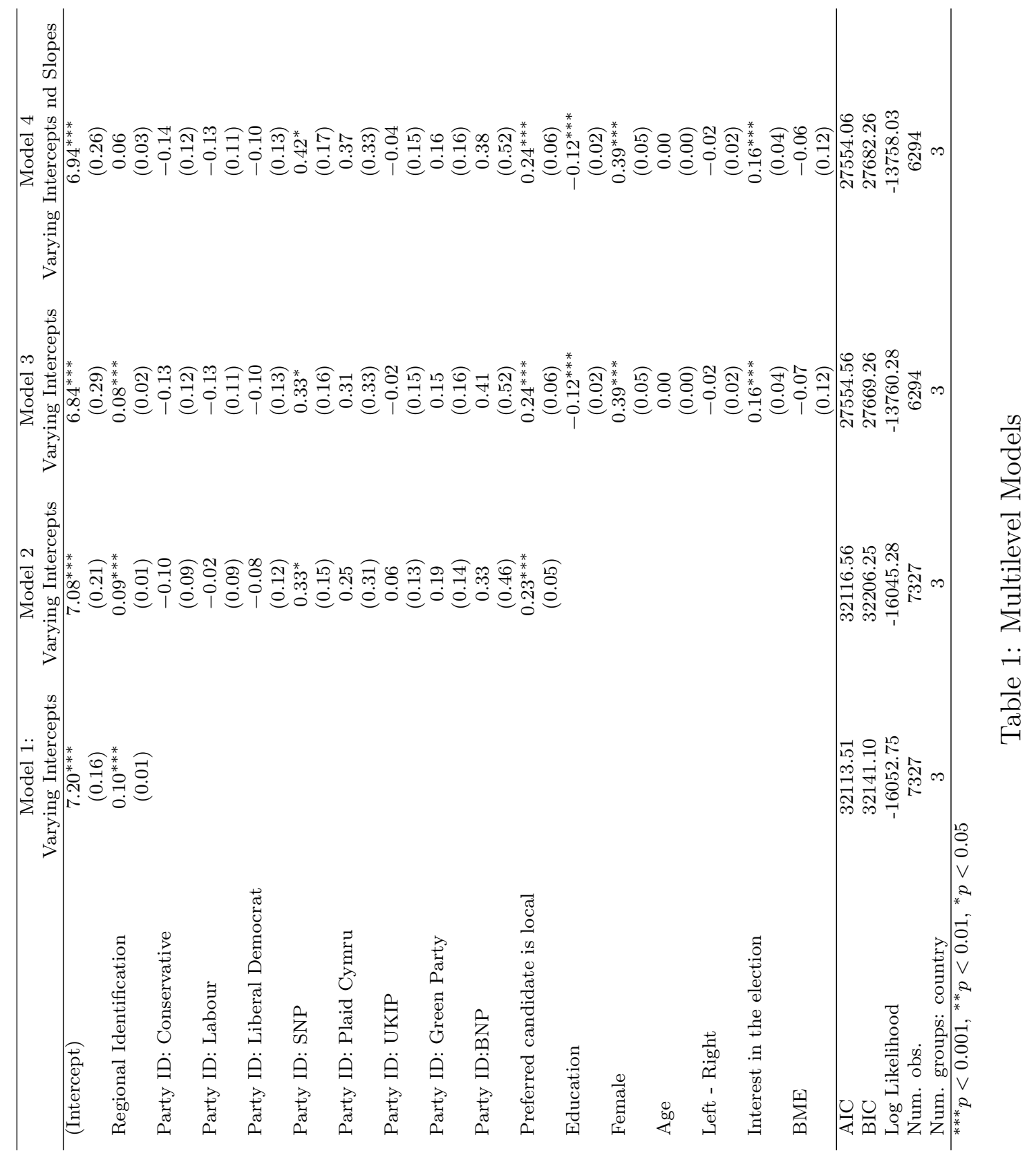




\section{Conclusions}

Previous research on descriptive representation have made the case of the importance of the local candidates. The electoral advantage of the local candidate has been explained by their better understanding of the local needs and voter's beliefs that they can be made accountable to the locality.

In this article, we have used data from the BES 2015 survey to isolate the effect from preferences for local MPs and strength of regional identities from campaign and canvasing activities. We found that individuals with stronger regional identities are more likely to care about localness. Results indicate that regional identities matter to express preferences for the local candidate, they are tied to geography but go beyond the boundaries of the constituency. We also show that in Scotland the regional identity can be channelled through the presence of a nationalist party, such as the SNP.

This findings can have broader implications for the study of candidates, voting behaviour and representation. They indicate that regional identities and the structure of party systems can permeate preferences for local candidates and can play a key role in achieving descriptive representation. While it is important to acknowledge that effects are specific to the British case, with strong political and regional identities clearly attached to a territorial dimension, the results can be applied to other contexts and countries with strong regional identities such as Canada, Spain or Belgium or with North/South divide such as the USA. They contribute to the advance of the literature in at least, two ways. Firstly, they demonstrate that a party can channel nationalistic feelings in different ways and secondly, that not all citizens consider the local candidate as their best option for being represented. 


\section{References}

Arzheimer, K. and Evans, J. (2012). Geolocation and voting: Candidate-voter distance effects on party choice in the 2010 uk general election in england. Political Geography, $31(5): 301-310$.

Bamberg, M., De Fina, A., and Schiffrin, D. (2011). Discourse and identity construction. In Handbook of identity theory and research, pages 177-199. Springer.

Bassi, A., Morton, R. B., and Williams, K. C. (2011). The effects of identities, incentives, and information on voting. The Journal of Politics, 73(2):558-571.

Bishop, B. (2008). The big sort: Why the clustering of like-minded America is tearing us apart. Houghton Mifflin Harcourt.

Blais, A. and Daoust, J.-F. (2017). What do voters do when they like a local candidate from another party? Canadian Journal of Political Science/Revue canadienne de science politique, pages 1-7.

Blais, A., Gidengil, E., Dobrzynska, A., Nevitte, N., and Adeau, R. (2003). Does the local candidate matter? candidate effects in the canadian election of 2000. Canadian Journal of Political Science/Revue canadienne de science politique, 36(03):657-664.

Campbell, R. and Cowley, P. (2014). What voters want: Reactions to candidate characteristics in a survey experiment. Political Studies, 62(4):745-765.

Carey, S. (2002). Undivided loyalties: is national identity an obstacle to european integration? European union politics, 3(4):387-413.

Chernyha, L. T. and Burg, S. L. (2012). Accounting for the effects of identity on political behavior: Descent, strength of attachment, and preferences in the regions of spain. Comparative Political Studies, 45(6):774-803. 
Childs, S. and Cowley, P. (2011). The politics of local presence: Is there a case for descriptive representation? Political Studies, 59(1):1-19.

Dandoy, R. and Schakel, A. (2013). Regional and national elections in Western Europe: territoriality of the vote in thirteen countries. Springer.

Dovi, S. (2002). Preferable descriptive representatives: Will just any woman, black, or latino do? American Political Science Review, 96(04):729-743.

Elff, M., Heisig, J. P., Schaeffer, M., and Shikano, S. (2016). No need to turn bayesian in multilevel analysis with few clusters: How frequentist methods provide unbiased estimates and accurate inference.

Fieldhouse, E.; Green, J. E. G. S. H. v. d. E. C. M. J. and Prosser, C. (2015). British election study 2015 constituency results version 2.2. http://www.britishelectionstudy.com/dataobject/2015-bes-constituency-results-with-census-and-candidate-data/.

Fieldhouse, E.; Green, J. E. G. S. H. v. d. E. C. M. J. and Prosser, C. (2016). British election study. http://dx.doi.org/10.5255/UKDA-SN-7972-.

Glasgow, G. and Alvarez, R. M. (2000). Uncertainty and candidate personality traits. American Politics Quarterly, 28(1):26-49.

Górecki, M. A. and Marsh, M. (2012). Not just 'friends and neighbours': canvassing, geographic proximity and voter choice. European Journal of Political Research, 51(5):563-582.

Hobolt, S. B. (2016). The brexit vote: a divided nation, a divided continent. Journal of European Public Policy, 23(9):1259-1277.

Hooghe, L. and Marks, G. (2004). Does identity or economic rationality drive public opinion on european integration? PS: Political Science 6 Politics, 37(3):415-420. 
Hooghe, L. and Marks, G. (2005). Calculation, community and cues: Public opinion on european integration. European Union Politics, 6(4):419-443.

Jankowski, M. (2016). Voting for locals: Voters' information processing strategies in open-list pr systems. Electoral Studies, 43:72-84.

Kumar, K. (2003). The making of English national identity. Cambridge University Press.

Mann, R. and Fenton, S. (2017). Nation, Class and Resentment: The Politics of National Identity in England, Scotland and Wales. Springer.

Marsh, M. (2007). Candidates or parties? objects of electoral choice in ireland. Party Politics, 13(4):500-527.

McAllister, I. (2015). The personalization of politics in australia. Party politics, 21(3):337345.

McCrone, D. and Bechhofer, F. (2015). Understanding national identity. Cambridge University Press.

Phillips, A. (1995). The politics of presence: Issues in democracy and group representation.

Reynolds, A. (2005). Reserved seats in national legislatures: A research note. Legislative Studies Quarterly, 30(2):301-310.

Roy, J. and Alcantara, C. (2015). The candidate effect: Does the local candidate matter? Journal of Elections, Public Opinion \& Parties, 25(2):195-214.

Rüdig, W., Sajuria, J., Hudson, J., and Collignon, S. (2016). Is the 'local candidate' advantage a myth? analysing the effects of localism in the 2015 uk general election. EPOP Conference 2016. 
Schnaudt, C., Walter, S., and Popa, S. A. (2016). Subnational and national territorial identification.

Shugart, M. S., Valdini, M. E., and Suominen, K. (2005). Looking for locals: voter information demands and personal vote-earning attributes of legislators under proportional representation. American Journal of Political Science, 49(2):437-449.

Stegmueller, D. (2013). How many countries for multilevel modeling? a comparison of frequentist and bayesian approaches. American Journal of Political Science, 57(3):748761.

Tavits, M. (2010). Effect of local ties on electoral success and parliamentary behaviour: The case of estonia. Party Politics, 16(2):215-235.

Tilley, J., Exley, S., and Heath, A. (2004). Dimensions of british identity. British social attitudes: The 21st report, pages 147-165.

Westle, B. (2011). Identity, social and political. In Badie, B., Berg-Schlosser, D., and Morlino, L., editors, International encyclopedia of political science, volume 1. Sage. 